\title{
A Quantitative Analysis of Photovoltaic Modules Using Halved Cells
}

\author{
S. Guo, ${ }^{1,2}$ J. P. Singh, ${ }^{1,2}$ I. M. Peters, ${ }^{1}$ A. G. Aberle, ${ }^{1,2}$ and T. M. Walsh ${ }^{1}$ \\ ${ }^{1}$ Solar Energy Research Institute of Singapore, National University of Singapore, 7 Engineering Drive 1, Block E3A, \#06-01, \\ Singapore 117574 \\ ${ }^{2}$ Department of Electrical and Computer Engineering, National University of Singapore, 7 Engineering Drive 1, Block E3A, \#06-01, \\ Singapore 117574
}

Correspondence should be addressed to S. Guo; guo_siyu@nus.edu.sg

Received 23 May 2013; Accepted 5 August 2013

Academic Editor: Chun-Sheng Jiang

Copyright (C) 2013 S. Guo et al. This is an open access article distributed under the Creative Commons Attribution License, which permits unrestricted use, distribution, and reproduction in any medium, provided the original work is properly cited.

In a silicon wafer-based photovoltaic (PV) module, significant power is lost due to current transport through the ribbons interconnecting neighbour cells. Using halved cells in PV modules is an effective method to reduce the resistive power loss which has already been applied by some major PV manufacturers (Mitsubishi, BP Solar) in their commercial available PV modules. As a consequence, quantitative analysis of PV modules using halved cells is needed. In this paper we investigate theoretically and experimentally the difference between modules made with halved and full-size solar cells. Theoretically, we find an improvement in fill factor of $1.8 \%$ absolute and output power of $90 \mathrm{~mW}$ for the halved cell minimodule. Experimentally, we find an improvement in fill factor of $1.3 \%$ absolute and output power of $60 \mathrm{~mW}$ for the halved cell module. Also, we investigate theoretically how this effect confers to the case of large-size modules. It is found that the performance increment of halved cell PV modules is even higher for high-efficiency solar cells. After that, the resistive loss of large-size modules with different interconnection schemes is analysed. Finally, factors influencing the performance and cost of industrial halved cell PV modules are discussed.

\section{Introduction}

Cell-to-module (CTM) losses are a concern for every silicon wafer-based PV module manufacturer. These CTM losses occur generally for one of two reasons: (1) optical losses that are caused by the module encapsulation processes, for example, increased reflectance loss, and parasitic absorptance losses in the cover glass and front encapsulant layer $[1,2]$ and (2) resistive losses due to the ribbons and the configuration of the silicon wafer solar cells inside the module.

The optical losses are given for a specific set of module materials (glass, EVA), and it is not possible to reduce these losses without changing materials (e.g., by using silicone encapsulant or applying an antireflection coating on the cover glass). Some investigations were already done in order to reduce the optical losses. For example, Kumar et al. [3] provided a method to optimise antireflective coatings of PV modules. In a publication by $\mathrm{Su}$ et al. [4], improving the output power by using a back sheet reflector was investigated.
There are also investigations on reducing resistive losses due to ribbons. Van Dyk and Meyer [5] discussed the influence from parasitic series and shunt resistances on the PV module performance. Caballero et al. [6] performed series resistance modelling of PV modules to optimise the front metal grid structure. Kumar et al. [3] showed that increasing the thickness of the copper ribbon and reducing the cell-to-cell gap could help reduce resistive power loss.

Using halved cells in PV modules is an effective method to reduce the resistive power loss. Halved cells are produced by cutting the normal full-size cells into half by laser, along a direction perpendicular to the busbars. After that, the halved cells are connected and packed into a PV module. This method has already been applied by some major PV manufacturers (Mitsubishi, BP Solar) in their commercial available PV modules [7, 8]. Also, the batch performance of such kind of PV modules has been reported by BP Solar in [9]. In this paper, we describe the theory behind the benefits of using halved cells in a silicon wafer-based PV module, 


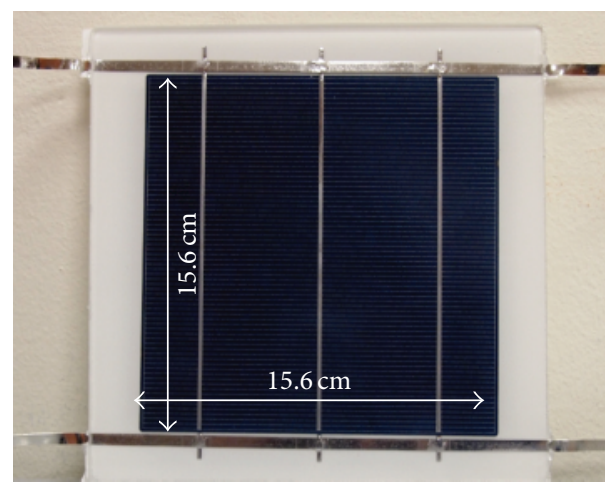

(a)

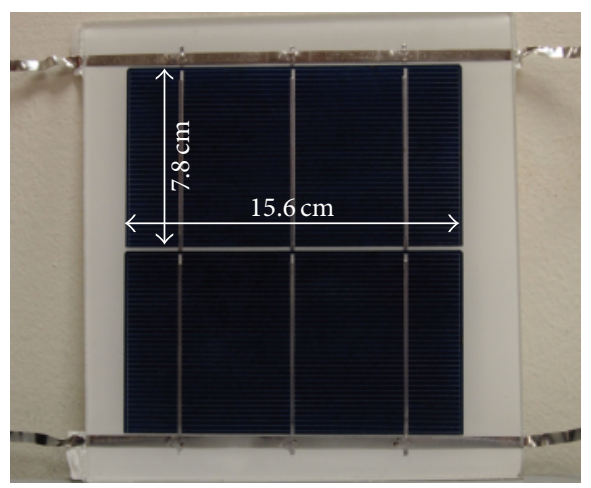

(b)

FIGURE 1: Photograph of minimodule with (a) one full-size solar cell and (b) two halved solar cells connected in series.

and we quantitatively analyse the magnitude of the benefit by simulation and experiment. In the theoretical section, we summarize the mathematics required to simulate the modules with cells cut into $n$ pieces and present a quantitative analysis on the module characteristics using LTSpice. Experimental results confirm the benefits of using halved cells on minimodules (see Figure 1). However, the measured improvement is smaller than the one theoretically predicted. Possible causes for this difference are losses occurring in the modularization process and the mismatch losses with the series connection of two halved cells.

It is a well-known fact that with the increase in short circuit current density of the cells, resistive losses increase. To show this effect, we have quantified the benefits of cutting cells into half for various short circuit current density values. It is observed that for high efficiency solar cells, when they are made into halved cell modules, the resistive loss is reduced by an even larger amount. After that, we discuss strategies for the configuration of industrial-size halved cell modules and the additional benefits that these modules can have at the system level. At last, factors influencing the performance and cost of industrial-size halved cell modules are discussed.

\section{Theory and Simulation}

2.1. Resistive Losses in Full-Size Cell and Halved Cell Minimodules. For a minimodule, such as shown in Figure 1, made from silicon wafer solar cells, the series resistance can be broken down into two parts: (a) the series resistance of the cell $\left(R_{c}\right)$, which includes bulk silicon resistance, metalsemiconductor contact resistance, and resistance of the metal electrodes, and (b) the series resistance of the ribbons $\left(R_{r}\right)$. In this analysis, we assume that the contact resistance between the busbars of the cell and the ribbons is negligible. We also neglect the resistance of the bussing ribbons which are wide and thick. In the real application, the cells can be cut into two or more pieces so that the resistive loss can be reduced.

The total series resistance of the minimodule $\left(R_{\mathrm{mm}}\right)$ with a full-size cell is then

$$
R_{\mathrm{mm}(\text { full })}=R_{c(\text { full })}+R_{r(\text { full })} .
$$

For the minimodule containing $n$ cut cells connected in series, the series resistance can be calculated as follows.

Since the lumped series resistance of a solar cell is inversely proportional to the cell area, we have

$$
R_{c(\text { cut })}=n R_{c(\text { full })} .
$$

And since $R_{r}$ is directly proportional to the ribbon length, we have

$$
R_{r(\mathrm{cut})}=\frac{1}{n} R_{r(\mathrm{full})} \text {. }
$$

In the minimodule with $n$ cut pieces of cells in series, the series resistances of the cells and ribbon add up; therefore

$$
\begin{aligned}
R_{\mathrm{mm}(\text { cut })} & =n\left(R_{c(\text { cut })}+R_{r(\text { cut })}\right) \\
& =n\left(n R_{c(\text { full })}+\frac{1}{n} R_{r(\text { full })}\right) \\
& =n^{2} R_{c(\text { full })}+R_{r \text { (full }) .}
\end{aligned}
$$

The effective current flowing through the minimodule with $n$ pieces cells is $1 / n$ times of that through the minimodule with full-size cells. Since the resistive power losses $\left(P_{\text {loss }}\right)$ are equal to the square of the current multiplied by the total series resistance, we have

$$
\begin{gathered}
P_{\text {loss (full) }}=I^{2}\left(R_{c(\text { full })}+R_{r(\text { full })}\right), \\
P_{\text {loss (cut) })}=\left(\frac{I}{n}\right)^{2}\left(n^{2} R_{c(\text { full })}+R_{r(\text { full })}\right) \\
=I^{2}\left(R_{c(\text { full })}+\frac{1}{n^{2}} R_{r(\text { full })}\right) .
\end{gathered}
$$

It can be observed that for cut-cell modules, the cell resistive loss remains the same, and the reduction on power loss is due to the reduced ribbon resistive loss. Thus, the relative power loss reduction on ribbon can be calculated as follows:

$$
\begin{aligned}
\text { reduction } & =\frac{P_{\text {ribbon loss (full) }}-P_{\text {ribbon loss (cut) }}}{P_{\text {ribbon loss (full) }}} \\
& =1-\frac{1}{n^{2}} .
\end{aligned}
$$



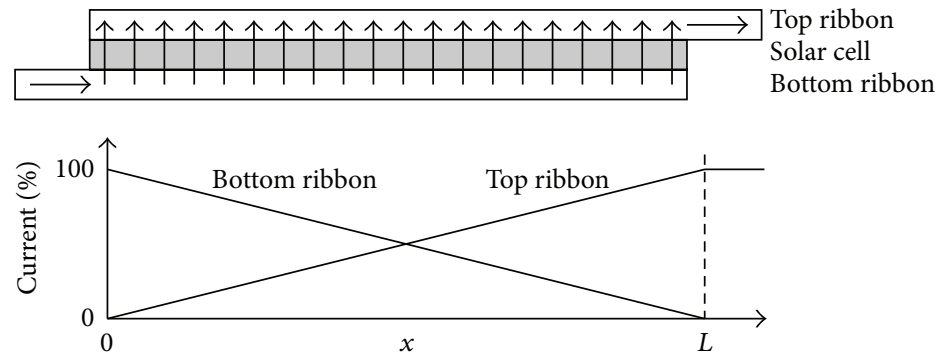

Figure 2: The current flows in a solar cell cross section with ribbons on both sides.

In all equations, $I$ is the current flowing through the full-size cell. Equation (6) shows that if we cut the solar cell into $n$ stripes, the power loss in the ribbon scales with a factor $1 / n^{2}$. Thus for halved cell module, the contribution of the ribbon resistance to the power loss will scale as $1 / 4$, that is, $75 \%$ reduction in power loss due to ribbon resistance. Equation (7) shows that the power loss on ribbon can be further reduced if a cell is cut into more pieces. However, the benefit of power loss reduction gets smaller when $n$ becomes larger. Also, cutting cells into more pieces might introduce more problems (mismatch effect and additional gaps between the cells). As a consequence, in this paper we only investigate PV modules with halved cells.

2.2. Calculation of Ribbon Resistance in a Module. In a module, we use tin-coated copper ribbons to interconnect the silicon wafer solar cells. For each solar cell, there is one ribbon on the top and one ribbon on the bottom. If the total current generated by one solar cell is $I_{L}$, the current in the top ribbon increases linearly from 0 to $I_{L}$ and the current in the bottom ribbon decreases linearly from $I_{L}$ to 0 across the length of the cell (as shown in Figure 2). of $x$ is

The current flowing through the top ribbon as a function

$$
I_{\text {top }}=I_{L} \frac{x}{L} .
$$

Similarly, the current flowing through the bottom ribbon is

$$
I_{\text {bottom }}=I_{L}\left(1-\frac{x}{L}\right) \text {. }
$$

Thus, the power loss in the top ribbon is

$$
P_{\text {loss_top }}=\int_{0}^{L}\left(I_{L} \frac{x}{L}\right)^{2} r \mathrm{~d} x=\frac{r L I_{L}^{2}}{3},
$$

where $r$ is the ribbon resistance per unit length, with a unit of $\Omega / \mathrm{cm}, L$ is the ribbon length, and $x$ is the current position along the ribbon.

Similarly, the power loss of the bottom ribbon is also $r L I_{L}^{2} / 3$; thus for each cell, the total power loss caused by ribbon resistance is $2 r L I_{L}^{2} / 3$. Since $P=I^{2} R$, the effective ribbon resistance $R_{r}$ of one cell is

$$
R_{r}=\frac{2 r L_{\mathrm{bb}}}{3 N_{\mathrm{bb}}},
$$

where $L_{\mathrm{bb}}$ is the busbar length and $N_{\mathrm{bb}}$ is the number of busbars.

2.3. Simulation Results. In order to calculate the gain in fill factor and output power when we go from a full-size cell minimodule to a halved cell minimodule, simulations were performed. PV module modelling was used in a variety of applications, especially for predicting the PV module performance under different conditions. Rosell and Ibanez [10] provided a numerical model that can accurately estimate the output power of a PV module in outdoor operating conditions. Mermoud and Lejeune [11] and Patel and Agarwal [12] used PVsyst and MATLAB based modelling, respectively, to research on PV module performance under partial shading conditions. In our simulation, we used a SPICE simulator called LTspice [13] to build integrated circuit models of the minimodules as shown in Figure 1. SPICE simulators were used before to simulate the behaviour of solar cells or PV modules [14-16]. Our model is based on the one-diode equivalent circuit. Circuit modelling for solar cells based on diode models is a well-established technique and has been used to investigate various scientific questions $[17,18]$. In this simulation, each solar cell in the module is represented by a one-diode model with additional resistors. The equivalent circuits are shown in Figure 3.

Models of both full-size cell module and halved cell module were constructed, and the corresponding module behaviour was simulated. All the parameters used in this simulation are shown in Table 1 . Among these parameters, all the cell parameters are obtained from fitting the parameters of one-diode model to the cells used to make the minimodules and all the ribbon parameters are obtained from direct measurements. All the values of the resistances used in the circuit model are shown in Table 2. The results of the performed simulations are shown in Table 3.

As per design, the $V_{\text {oc }}$ of the halved cell module is expected to be two times of the $V_{\text {oc }}$ of the full-size cell module, whereas the $I_{\mathrm{sc}}$ of the halved cell module is expected to be half of the $I_{\mathrm{sc}}$ of the full-size cell module. Because of the reduced resistive loss, the fill factor and, consequently, the output power of halved cell minimodule are higher than those of the full-size cell minimodule. For the cell described by parameters as shown in Table 1, the simulation results show about $1.8 \%$ absolute increase in FF of the module which accounts for an output power increase of $90 \mathrm{~mW}$ 
TABLE 1: The parameters used in this simulation.

\begin{tabular}{|c|c|c|c|c|c|c|c|c|}
\hline Parameter & $R_{\mathrm{s}}$ & $R_{\mathrm{sh}}$ & $n$ & $J_{L}$ & $J_{0}$ & $\rho$ & $w$ & $d$ \\
\hline Value & $0.6 \Omega \cdot \mathrm{cm}^{2}$ & $10000 \Omega \cdot \mathrm{cm}^{2}$ & 1.02 & $34.29 \mathrm{~mA} / \mathrm{cm}^{2}$ & $2 \times 10^{-12} \mathrm{~A} / \mathrm{cm}^{2}$ & $1.728 \times 10^{-8} \Omega \cdot \mathrm{m}$ & $1.5 \mathrm{~mm}$ & $200 \mu \mathrm{m}$ \\
\hline
\end{tabular}

$R_{s}$ is the cell series resistance, $R_{\mathrm{sh}}$ is the cell shunt resistance, $n$ is diode ideality factor, $J_{0}$ is reverse saturation current density, $\rho$ is ribbon resistivity, $w$ is ribbon width, and $d$ is ribbon thickness.

TABLE 2: The values of the resistances used as input in the circuit model. (Calculated from the method shown in Section 2.2).

\begin{tabular}{lcccc}
\hline Resistance & $R_{c(\text { full })}$ & $R_{r(\text { full })}$ & $R_{c(\text { half })}$ & $R_{r(\text { half })}$ \\
\hline Value & $2.465 \times 10^{-3} \Omega$ & $1.996 \times 10^{-3} \Omega$ & $1.232 \times 10^{-3} \Omega$ & $0.998 \times 10^{-3} \Omega$ \\
\hline
\end{tabular}

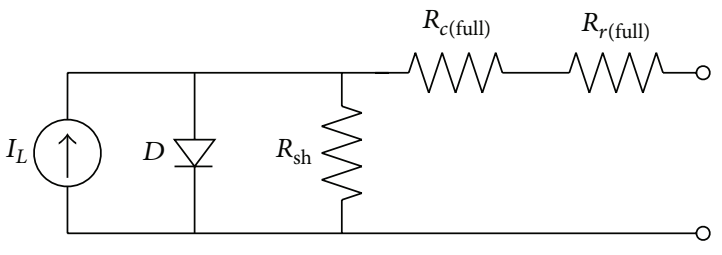

(a)
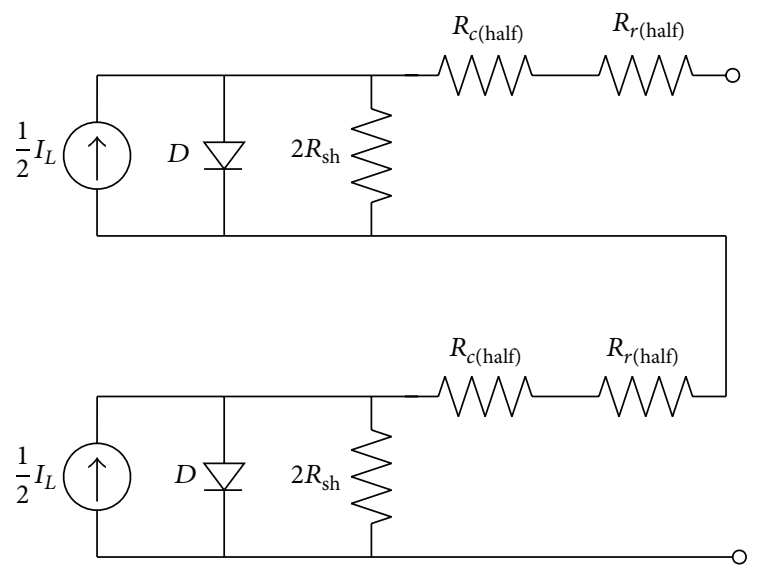

(b)

FIGURE 3: The equivalent circuit models built in LTspice: (a) a fullsize cell minimodule composed of one full-size cell and (b) a halved cell minimodule composed of two halved cells connected in series.

(2.2\% relative). These results show that using halved cells instead of full-size cells can considerably improve the module performance.

The simulation results shown in Table 3 are for solar cells with moderate efficiency (moderate $j_{\text {sc }}$ ). However, for some high-efficiency solar cells today, the short circuit current can reach more than $40 \mathrm{~mA} / \mathrm{cm}^{2}$. For these high-efficiency solar cells, the cell-to-module loss is increasing due to resistive loss on ribbon, and the benefit of using halved cell modules will be even larger. This is because that as described in Section 2.1, the power loss reduction for halved cell modules scales with $I^{2}$. Table 4 shows the simulation results done for solar cells with short circuit current density of $42 \mathrm{~mA} / \mathrm{cm}^{2}$. All other cell parameters are the same as shown in Table 1.

From the simulation results shown in Table 4, for a solar cell with $j_{\mathrm{sc}}$ of $42 \mathrm{~mA} / \mathrm{cm}^{2}$, the fill factor of the halved cell
TABLE 3: The simulated one-sun $I-V$ characteristics of the halved cell and the full-size cell mini-modules.

\begin{tabular}{lcccc}
\hline Module type & $I_{\mathrm{sc}}[\mathrm{A}]$ & $V_{\mathrm{oc}}[\mathrm{V}]$ & Fill factor [\%] & Power [W] \\
\hline Halved cell & 4.17 & 1.24 & 79.3 & 4.10 \\
Full-size cell & 8.34 & 0.620 & 77.5 & 4.01 \\
\hline
\end{tabular}

TABLE 4: The simulated one-sun $I-V$ characteristics of the halved cell and the full-size cell mini-modules.

\begin{tabular}{lcccc}
\hline Module type & $I_{\mathrm{sc}}[\mathrm{A}]$ & $V_{\mathrm{oc}}[\mathrm{V}]$ & Fill factor [\%] & Power $[\mathrm{W}]$ \\
\hline Halved cell & 5.11 & 1.25 & 78.6 & 5.02 \\
Full-size cell & 10.22 & 0.627 & 76.4 & 4.88 \\
\hline
\end{tabular}

minimodule is $2.2 \%$ higher than that of the full-size cell minimodule. The power output for the halved cell minimodule increases by $130 \mathrm{~mW}$ or $2.9 \%$ relative. This suggests that for solar cells with higher $j_{\mathrm{sc}}$, the cell-to-module resistive loss can be reduced by a larger extent as compared to the solar cells with moderate/low $j_{\text {sc }}$. A further analysis on the relation between loss reduction in modules and $j_{\mathrm{sc}}$ of the solar cell is given in Section 4.

\section{Experiments}

3.1. Experimental Details. To verify the observed simulation results, minimodules with halved cells and full-size cells were fabricated. For the present experimental study, we have compared four samples of each type of modules. Note that originally six halved cell minimodules were produced, but two of them were damaged during processing and were not used in the analysis. The multi-Si wafer solar cells used to fabricate these modules were chosen from the same batch with cell efficiencies in the range of $17.2-17.4 \%$. A Qswitched, picosecond, and frequency doubled Nd:YAG laser was used to cut the cells into halves (Lumera SUPER RAPID, Lumera Laser, Germany). The equipment, materials, and soldering conditions were the same for all samples during soldering and busbar connection processes. After that, all samples were laminated at the same time and under the same temperature conditions using our standard lamination recipe. The arrangement of halved cells used generates an open-circuit voltage approximately equal to twice the full-size cell minimodule and a short-circuit current approximately equal to half of the full-size cell minimodule. To compare the halved cell minimodules and full-size cell minimodules, 
TABLE 5: The measured average values of one-sun $I-V$ characteristics of the halved cell modules and full-size cell modules.

\begin{tabular}{lcccc}
\hline Module type & $I_{\mathrm{sc}}[\mathrm{A}]$ & $V_{\mathrm{oc}}[\mathrm{V}]$ & Fill factor [\%] & Power [W] \\
\hline Halved cell & 4.17 & 1.24 & 78.9 & 4.08 \\
Full-size cell & 8.35 & 0.620 & 77.6 & 4.02 \\
\hline
\end{tabular}

all fabricated module samples were measured under standard test conditions (STC) using a steady-state super-class-A, solar simulator (SolSim 210, Aescusoft, Germany).

3.2. Experimental Results. The average values of various electrical one-sun parameters of the minimodules with one full-size cell and two halved cells are shown in Table 5.

As discussed earlier, the two types of modules differ only in the resistive losses because of the difference in the current generation. Hence, the fill factor and output power were chosen as figures of merit. The box plots of the fill factor and power for the two types of modules are shown in Figures 4(a) and 4(b), respectively. For minimodules with two halved cells, it can be observed that the fill factor is increased by $1.3 \%$ absolute on average and that the power is increased by $60 \mathrm{~mW}$ or $1.5 \%$ relative on average as compared to minimodules with one full-size cell. Assuming that the cell properties are influenced to some extent by the modularisation processing, the increase in fill factor and efficiency are in reasonable agreement with the simulation results. The difference between simulation and experimental results is probably due to the additional shunting problem caused by laser cutting and the mismatch effect between the two halved cells.

\section{Extension to Large-Size Modules by Simulation}

4.1. Resistive Loss for Large-Size Modules. In Section 2.3, we made a comparison between minimodules that are composed of solar cells with two different $j_{\text {sc }}$ values. In this part we extend the simulation to large-size modules and investigate the effect of cell $j_{\text {sc }}$ on resistive loss for large-size modules. A large-size module is composed of 60 solar cells connected in series. In Figure 5, the power loss on ribbon for halved and full-size cell modules with various cell $j_{\mathrm{sc}}$ values is plotted. From Figure 5, it can be observed that when the short circuit current density increases, the power loss on ribbon also increases. However, the increase on power loss is much larger for full-size cell module than that for halved cell modules. This means that using halved cell PV modules instead of full-size cell PV modules can help in keeping the power loss on ribbon within a small range for solar cells with higher short circuit current density. In Figure 5, we also compared this method with another method, reducing the resistive loss by increasing the ribbon thickness. The dash line shows the power loss when the ribbon thickness is increased from $0.2 \mathrm{~mm}$ to $0.25 \mathrm{~mm}$. Since resistive loss varies linearly with ribbon thickness for particular cell $j_{s c}$, the reduction in power loss on ribbon is much lower as compared with using halved cell modules. Also, increasing the thickness of ribbons

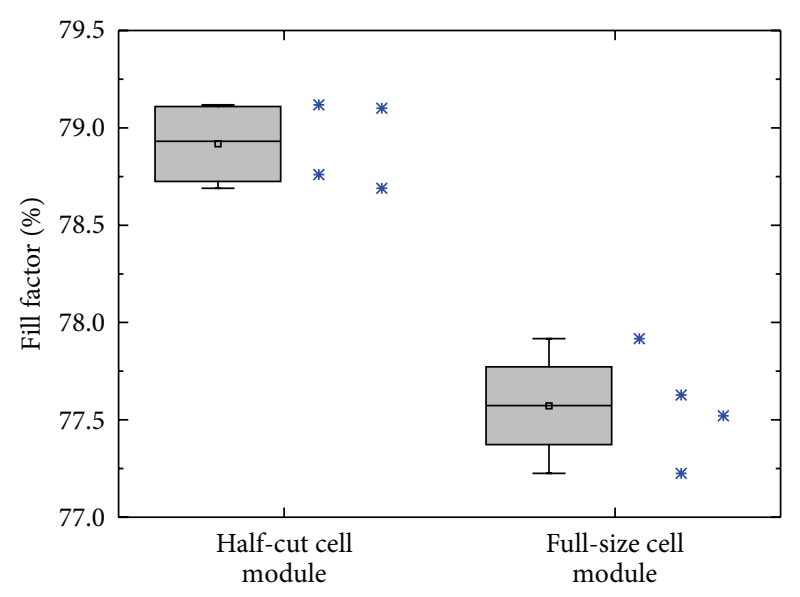

(a)

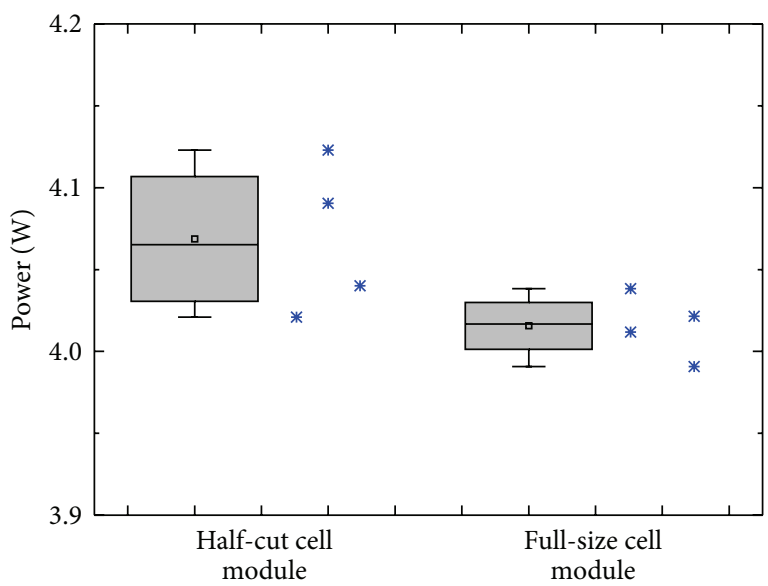

(b)

FIgURE 4: Box plot of the measured (a) fill factors and (b) output powers of halved cell minimodules and full-size cell minimodules under standard testing conditions and steady-state illumination.

leads to increase in cell breakage during manufacturing. Thus, compared with increasing the ribbon thickness, using halved cells is an effective method to reduce cell-to-module resistive loss for high $j_{\text {sc }}$ (high efficiency) solar cells.

4.2. Resistive Loss for Large-Size Modules. In order to take configurations of large-size modules into account, we performed simulations using a circuit model to simulate largesize modules. The investigated module structures are shown in Figure 6 as follows:

(a) the structure of a traditional large-size module is composed of 60 full-size cells;

(b) the structure of a large-size module composed of 120 halved cells connected in series;

(c) shows the structure of a large-size module is composed of 144 halved cells connected in both parallel and series.

Type $\mathrm{c}$ is similar to the commercially available PV modules of Mitsubishi. Type b and type $c$ represent two 


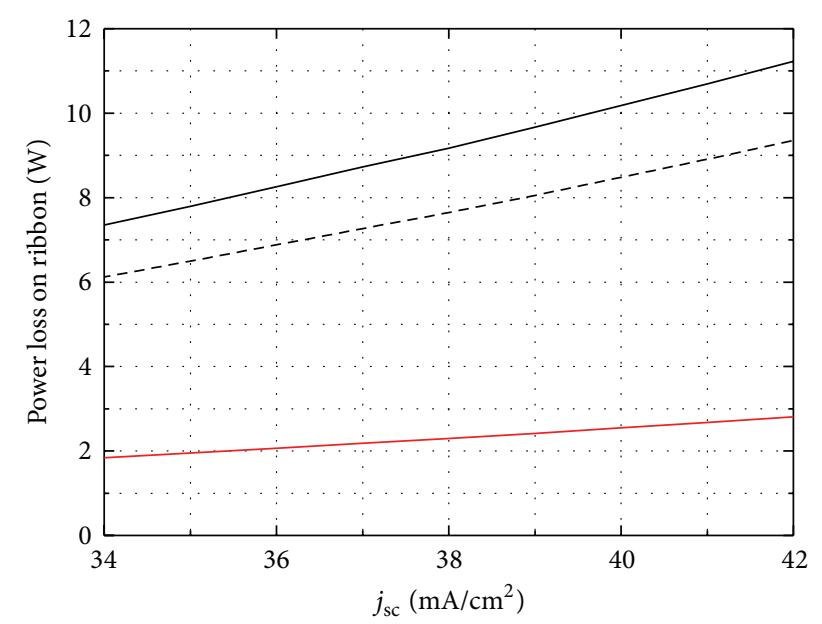

— Full-size cell module; ribbon thickness $=0.2 \mathrm{~mm}$

- - - Full-size cell module; ribbon thickness $=0.25 \mathrm{~mm}$

- Halved cell module; ribbon thickness $=0.2 \mathrm{~mm}$

(a)

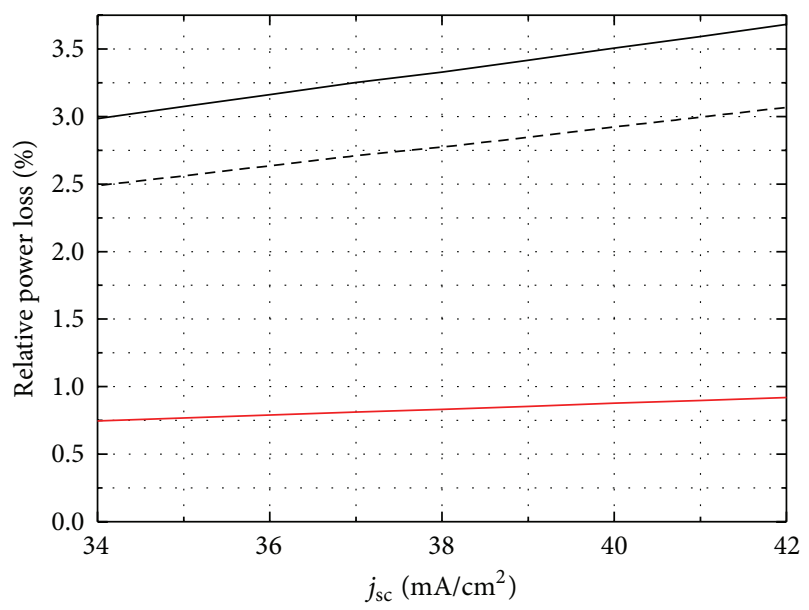

— Full-size cell module; ribbon thickness $=0.2 \mathrm{~mm}$

- - - Full-size cell module; ribbon thickness $=0.25 \mathrm{~mm}$

- Halved cell module; ribbon thickness $=0.2 \mathrm{~mm}$

(b)

Figure 5: (a) Power loss on ribbon for halved and full-size cell largesize PV modules with various short circuit current density values. (b) The relative power loss is the percentage of resistive power loss on ribbon among all resistive losses. Two values of ribbon thickness are considered.

different methods to connect halved cells in a module. For the type-b module, all cells are connected in series; thus, the current of this module is half of the current of the type-a module, and the voltage is two times of the voltage of the type-a module. The type-c module contains twelve strings, and each string contains twelve halved cells. Each two strings are connected in parallel first, and then pairs of strings are connected in series. The short-circuit current of this module is the same as the short-circuit current of the type-a module.

Simulations were performed to compare the three module types. The main differences between the different module

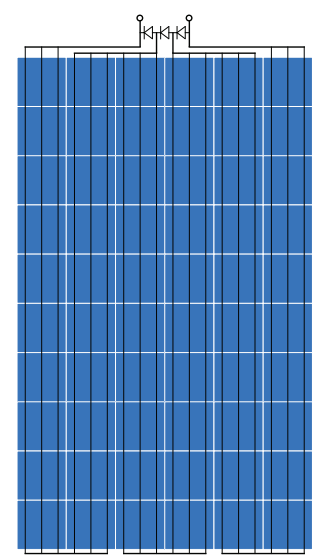

(a)

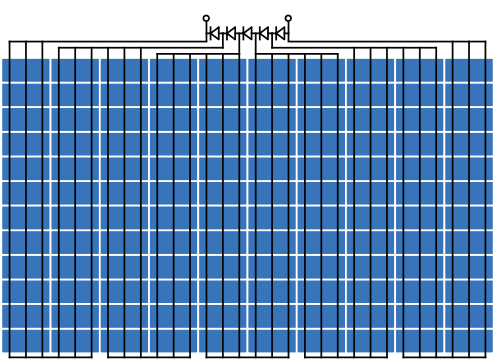

(b)

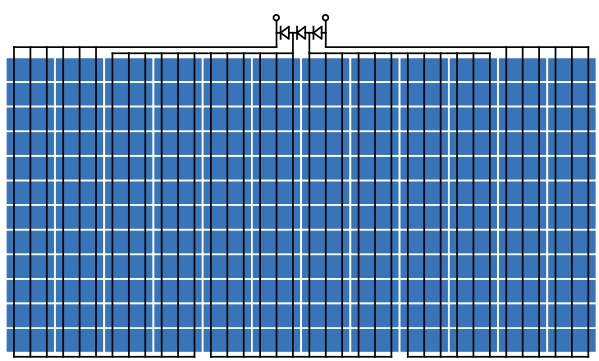

(c)

FIgURE 6: (a) Traditional large-size module that is composed of 60 full-size cells connected in series; (b) large-size module that is composed of 120 halved cells connected in series; (c) large-size module that is composed of 144 halved cells connected both in parallel and in series.

types are the total length of bussing ribbons and the current flowing through these ribbons. For this reason, the power loss caused by bussing ribbons has to be taken into consideration. In the simulations, the relationship of fill factor and effective series resistance was calculated from the diode equation. Then the effective series resistance of each type of module was calculated. After that, the fill factor of each type of module corresponding to its effective series resistance was obtained from the fill factor-effective resistance relationship. The resistance of the ribbon in the gaps between the two halves of a halved solar cell was also taken into account.

The fill factors corresponding to each type of PV module were calculated according to their effective series resistance which includes effective cell resistance, ribbon resistance, bussing ribbon resistance, and junction-box cable resistance. The simulation results are shown in Table 6 . The parameters used are as follows: bussing ribbon width: $5 \mathrm{~mm}$; bussing ribbon thickness: $0.3 \mathrm{~mm}$; cable cross-section area: $4 \mathrm{~mm}^{2}$; and cable length: $1 \mathrm{~m}$. All parameters were obtained experimentally.

From the simulation results shown in Table 6 , it can be observed that the fill factors of the two types of halved cell modules ((b) and (c)) are both higher than the traditional full-size cell module (a). The fill factors of the type-b and type$\mathrm{c}$ modules are different because of the different interconnection schemes. There are mainly two reasons: firstly, the total 
TABLE 6: Fill factors and total length of bussing ribbon of the three types of large-size modules investigated. Parameters used are as follows: bussing ribbon width: $5 \mathrm{~mm}$; bussing ribbon thickness: $0.3 \mathrm{~mm}$; cable cross-section area: $4 \mathrm{~mm}^{2}$; and cable length: $1 \mathrm{~m}$. All parameters were obtained experimentally.

\begin{tabular}{lccc}
\hline Module type & $\begin{array}{l}\text { (a) Full-size } \\
\text { cell module }\end{array}$ & $\begin{array}{c}\text { (b) Halved } \\
\text { cell module }\end{array}$ & $\begin{array}{c}\text { (c) Halved } \\
\text { cell module }\end{array}$ \\
\hline $\begin{array}{l}\text { Total effective series } \\
\text { resistance }\left(\mathrm{Ohm} \cdot \mathrm{cm}^{2}\right)\end{array}$ & 1.15 & 0.75 & 0.80 \\
$\begin{array}{l}\text { Fill factor }(\%) \\
\text { Total length of bussing }\end{array}$ & 77.1 & 79.1 & 78.8 \\
$\begin{array}{l}\text { ribbon }(\mathrm{cm}) \\
\begin{array}{l}\text { Ribbon length per } \\
\text { full-size wafer }(\mathrm{cm})\end{array}\end{array}$ & 218.4 & 384.8 & 468 \\
\hline
\end{tabular}

length of bussing ribbons of a type-c module is longer than that of a type-b module, secondly, for a type-b module, the current flowing through all the ribbons is half of the current of the traditional full-size type-a module.

However, since the type-c module includes parallel connection of strings, some bussing ribbons have the same current as the type-a module, and the higher current causes a higher power loss. Thus in real application, type-b module might be a better choice, since the series resistance loss at the module level for this type of module is the lowest. What is more, from the system level, type-b module will always result in lower resistive losses in all the cable connections that are used, since this kind of module has less current output than the traditional full-size cell module at the same power level. Parallel connection among module strings can be realised at the system level to achieve the required current and voltage for a standard inverter.

\section{Discussion}

The analysis presented so far has shown what the benefits in terms of power output are when using halved cells instead of full-size cells for PV modules. However, there are several additional factors that need to be considered, when those two configurations are compared.

(1) The fabrication process for full-sized and halved module cells is different. An additional laser cutting step is needed for halved cell modules, which introduces additional cost.

(2) Cutting solar cells in half is a potentially harmful process. The main threats are shunts induced by laser cutting and additional edge recombination. Performed experiments have shown that, for the best cell, theoretical predictions and experimental results of power output improvement are quite close. However, in three of four cases, the experimental results fall short of the theoretically expected improvement (see Figure 4). This is an indication that processing was not yet optimized. One possible reason may be a reduction in shunting resistance. Edge isolation seems to work efficiently as the open circuit voltage decreases by less than $1 \mathrm{mV}$ (see Table 5 ).
(3) Additional mismatch losses may be introduced by cutting the cells into half. This might be another possible reason of the difference between the theoretical prediction and measurement results.

(4) Halved cells introduce additional gaps in the module, which result in additional cost of the ribbons. For the ribbons connecting the cells in the module, the total length increase is $0.6 \mathrm{~cm}$ per full-size wafer $(1.2 \%$ relative). The bussing ribbon length used by halved cell modules also increases (Table 6).

(5) The additional gaps between the halved cells in the module lead to an increase in the total area of the module by $0.7 \%$ relative. This change in area does not affect the power output, but it reduces the module efficiency.

From simulation, if taking all the reduction of resistive loss from ribbons, the power generation efficiency can be improved by $2.1 \%$ relative for type-b module and $2.6 \%$ relative for type-c module. This means that for a standard $240 \mathrm{~W}$ industrial PV module with full-size solar cells, the power increase can be as much as $6.3 \mathrm{~W}$ if it is made into a halved cell module. What is more, the output power improvement is even larger for high-efficiency solar cells (as proved in Section 4.1). Besides, the cells which are locally shunted/damaged during fabrication process can be partially utilized by cutting them into half. Therefore, even though there might be some side effects as discussed above, the advantages of applying halved cell PV modules are still significant.

\section{Conclusion}

In this paper, we presented a detailed theoretical and experimental analysis of the resistive losses in PV modules with full-size and halved silicon wafer solar cells. Due to a quadratic dependence of the power loss on the current, it is advantageous to decrease the current flow in a module and increase the voltage. We investigated this situation using minimodules as test vehicles. A minimodule includes only a single silicon wafer solar cell, that is, either one full-size or two halved cells, but it has otherwise all other features of a largescale module. First, the minimodule was simulated using circuit simulation. In this simulation, we observed that the fill factor of the minimodule with halved cells was increased by $1.8 \%$ absolute, compared to the minimodule with the fullsize cell. This increase is solely an effect of the decreased power loss in the ribbon. Several minimodules of each type were fabricated, and one-sun current-voltage characteristics were measured. On average, we found an improvement in fill factor of $1.3 \%$ absolute and in output power of $60 \mathrm{~mW}$ or $1.5 \%$ relative when comparing the halved cell modules to full-size cell modules. Further simulations were performed for large-size PV modules. Our simulation results show that using halved cell modules instead of full-size cell modules is even more advantageous for solar cells with high short circuit current density (high efficiency). Also, we investigated the resistive losses for three different configurations of large-size modules (one with full-size cells and two with halved cells). 
In all cases, we found that a considerable improvement in fill factor occurred for the modules with halved cells. For the best investigated configuration, we found an increase in fill factor of $2 \%$ absolute from $77.1 \%$ to $79.1 \%$. We also discussed the associated problems with halved cell modules. Despite of these problems, the gain in terms of power/efficiency is considerable, and this method has potential for cost reduction of PV modules especially while using high efficiency solar cells.

In all, in this paper we did a detailed quantitative analysis of PV modules using halved cells. The improvement for both minimodules and industrial-size modules using halved cells are calculated, and analysed. These results will have significant impact on the design of silicon wafer-based PV modules and their performance evaluation.

\section{Acknowledgments}

The authors would like to thank their colleagues from the silicon photovoltaics cluster of the Solar Energy Research Institute of Singapore (SERIS) for their assistance in sample processing and measurements. SERIS is sponsored by the National University of Singapore (NUS) and Singapore's National Research Foundation (NRF) through the Singapore Economic Development Board (EDB).

\section{References}

[1] S. Krauter and R. Hanitsch, "Actual optical and thermal performance of PV-modules," Solar Energy Materials and Solar Cells, vol. 41-42, pp. 557-574, 1996.

[2] Y. S. Khoo, T. M. Walsh, F. Lu, and A. G. Aberle, "Method for quantifying optical parasitic absorptance loss of glass and encapsulant materials of silicon wafer based photovoltaic modules," Solar Energy Materials and Solar Cells, vol. 102, pp. 153158, 2012.

[3] N. D. Kumar, C. Mounika, T. Sailaja, and D. Mounika, "Design and reduction of wattage losses in solar module using AR coating, cell-to-cell gap and thickness," in Proceedings of the $3 \mathrm{rd}$ International Conference on Electronics Computer Technology (ICECT '11), pp. 42-47, Hyderabad, India, April 2011.

[4] W.-S. Su, Y.-C. Chen, W.-H. Liao et al., "Optimization of the output power by effect of backsheet reflectance and spacing between cell strings," in Proceedings of the 37th IEEE Photovoltaic Specialists Conference, pp. 3218-3220, Seattle, Wash, USA, 2011.

[5] E. E. van Dyk and E. L. Meyer, "Analysis of the effect of parasitic resistances on the performance of photovoltaic modules," Renewable Energy, vol. 29, no. 3, pp. 333-344, 2004.

[6] L. J. Caballero, P. Sánchez-Friera, B. Lalaguna, J. Alonso, and M. A. Vázquez, "Series resistance modelling of industrial screen-printed monocrystalline silicon solar cells and modules including the effect of spot soldering," in Proceedings of the 4th World Conference on Photovoltaic Energy Conversion (WCPEC4 '06), pp. 1388-1391, Waikolo, Hawaii, USA, May 2006.

[7] http://www.mitsubishielectric.com/bu/solar/pv_modules/pdf/ monocrystalline.pdf.

[8] http://www.mitsubishielectric.com/bu/solar/pv_modules/ monocrystalline/technologies.html.

[9] D. W. Cunningham, J. H. Wohlgemuth, R. F. Clark et al., "Reaching grid parity using BP solar crystalline silicon technology," in
Proceedings of the 35th IEEE Photovoltaic Specialists Conference (PVSC '10), pp. 1197-1202, Honolulu, Hawaii, USA, June 2010.

[10] J. I. Rosell and M. Ibáñez, "Modelling power output in photovoltaic modules for outdoor operating conditions," Energy Conversion and Management, vol. 47, no. 15-16, pp. 2424-2430, 2006.

[11] A. Mermoud and T. Lejeune, "Partial shading on PV arrays: bypass diode benefits analysis," in Proceedings of the 25th European Photovoltaic Solar Energy Conference, pp. 4654-4658, Valencia, Spain, 2010.

[12] H. Patel and V. Agarwal, "MATLAB-based modeling to study the effects of partial shading on PV array characteristics," IEEE Transactions on Energy Conversion, vol. 23, no. 1, pp. 302-310, 2008.

[13] M. Engelhardt, “LTSpice/SwitcherCAD IV," Linear Technology Corporatipn, 2011.

[14] S. Silvestre, A. Boronat, and A. Chouder, "Study of bypass diodes configuration on PV modules," Applied Energy, vol. 86, no. 9, pp. 1632-1640, 2009.

[15] L. Castaner and S. Silvestre, Modelling PhotoVoltaic Systems Using PSpice, John Wiley and Sons, New York, NY, USA, 2002.

[16] A. Zekry and A. Y. Al-Mazroo, "A distributed SPICE-model of a solar cell," IEEE Transactions on Electron Devices, vol. 43, no. 5, pp. 691-700, 1996.

[17] D. Grote, Analyses of Silicon Solar Cells and Their Measurement Methods by Distributed, Circuit Simulations and by Experiment [Ph.D. thesis], University of Konstanz, Baden-Württemberg, Germany, 2010.

[18] P. O. Grabitz, U. Rau, and J. H. Werner, "A multi-diode model for spatially inhomogeneous solar cells," Thin Solid Films, vol. 487, no. 1-2, pp. 14-18, 2005. 

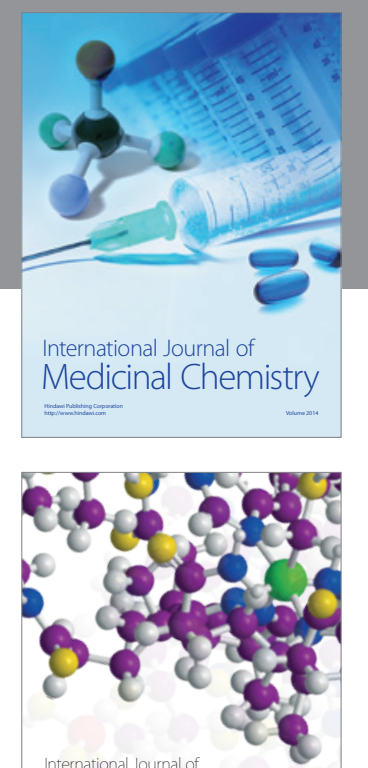

\section{Carbohydrate} Chemistry

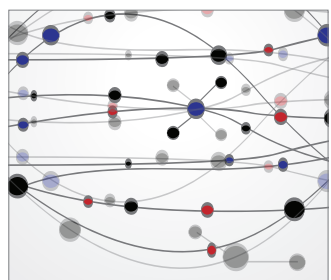

The Scientific World Journal
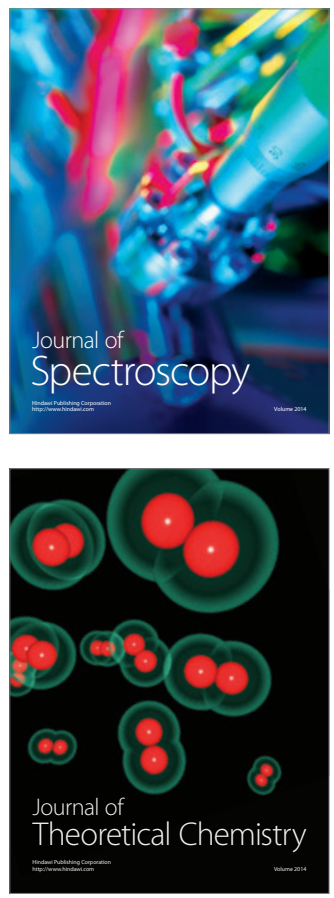
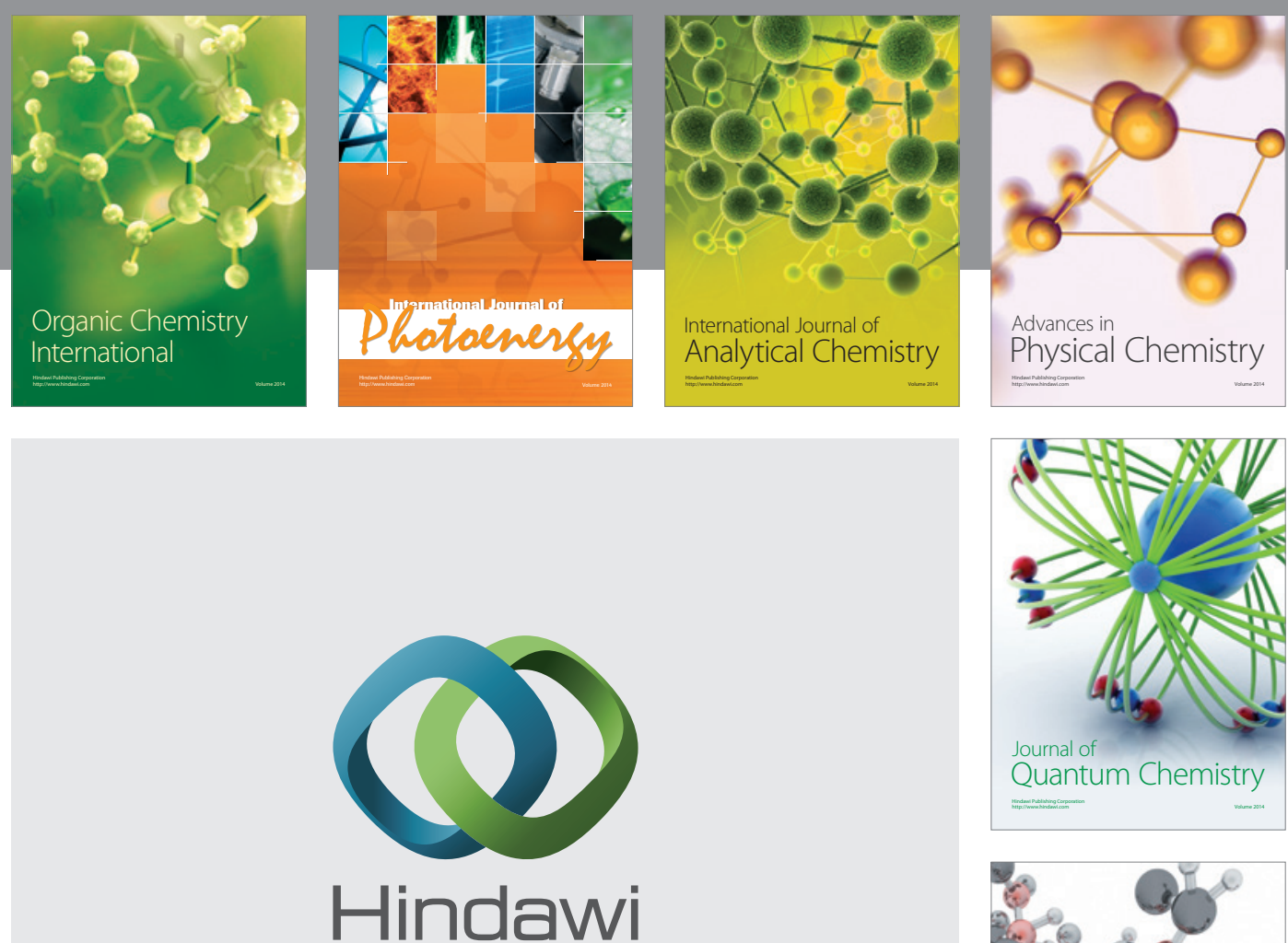

Submit your manuscripts at

http://www.hindawi.com

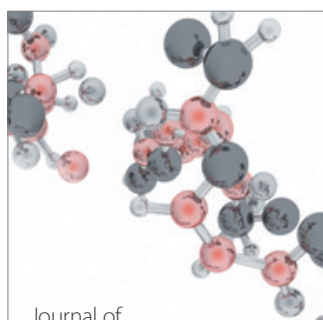

Analytical Methods

in Chemistry

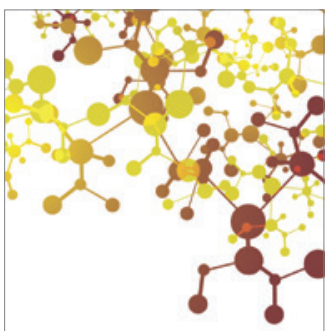

Journal of

Applied Chemistry

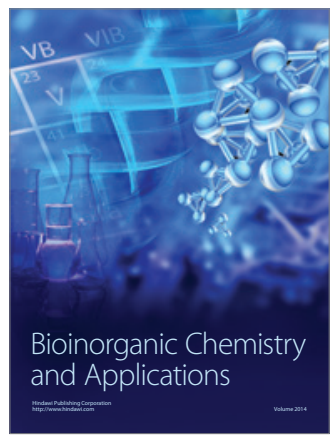

Inorganic Chemistry
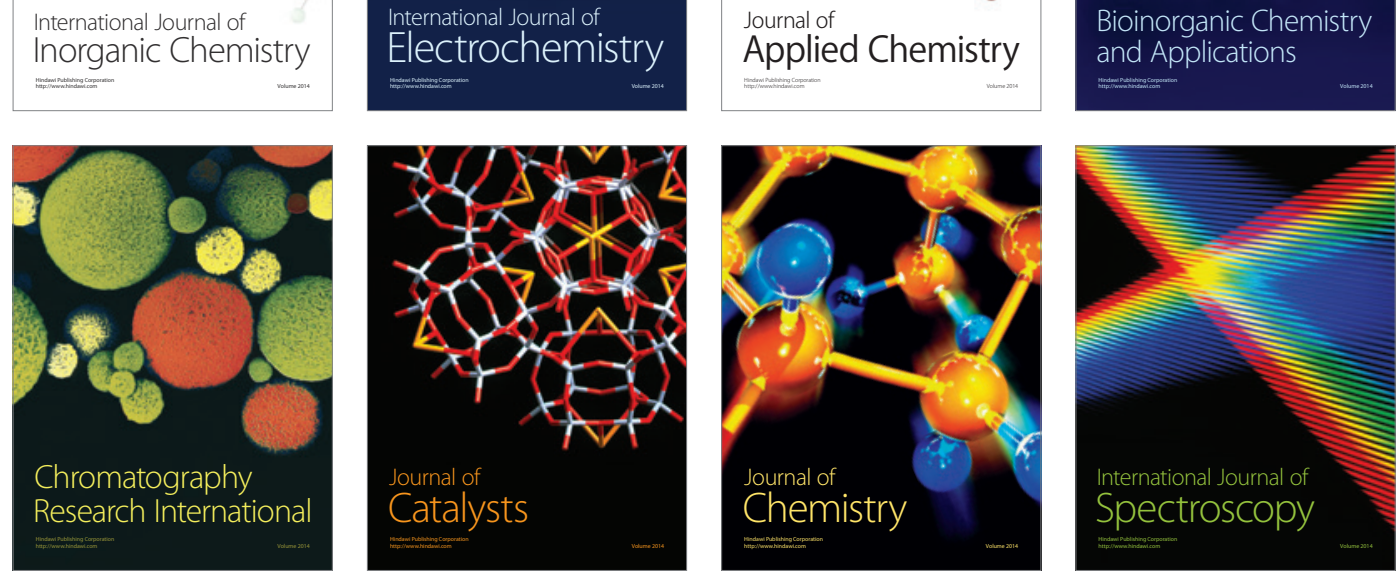